problems in research. Ron Vale, a molecular pharmacologist at the UCSF, really put the issue of increasing time to publication on the table (R. D. Vale Proc. Natl Acad. Sci. USA 112, 13439-13446; 2015) and organized the rest of us to launch ASAPbio as an independent spin-off group last year. My volunteering with policy groups and experience in organizing meetings and conducting outreach helped to soften my transition to director of ASAPbio in August.

ASAPbio is trying to promote the most productive use of preprints in biology. We see preprinting in other fields - physics, computer science and maths - as a way to address problems that early-career researchers experience most acutely. Having a long time to publication strains early careers, limits feedback on work through a closed peer-review process and slows the pace of science.

Transmission of knowledge is the foundation on which all major discoveries are built. We want to accelerate that process. Preprints are not widely used in biology. There's a general lack of awareness about them and they're not part of our culture. We're trying to encourage scientists to have conversations about preprints.

I hear two main concerns about preprints. The first is that they will disqualify authors from publication in toptier journals. That's not true. There's been a remarkable trend of acceptance of these practices at journals in the past few years.

The second is that preprint users will get scooped. This is a valid concern, but one that will be easily remedied as more and more people use them.

In other fields, preprints are cited, and treated as a first-class research product. If we want this in biology, we need to create the infrastructure, including the introduction of standards.

The rise of social media has enabled people to compare their experiences and to coordinate themselves better. In the past, this was possible only through more formal channels. As people debate the more conservative and radical positions on preprints in the public arena of Twitter, anyone can read them and take part in the discussion. People are also starting to share their first preprints with the hashtag \#ASAPbio.

I would like to see more than 100,000 biology preprints posted each year by 2020 . That would represent $10 \%$ of the volume of manuscripts that appear on PubMed annually. It would roughly equal the number in physics, too. This is an ambitious number, so I'll consider any increase a win.

\section{INTERVIEWS BY VIRGINIA GEWIN}

These interviews have been edited for length and clarity.

\title{
TURNING POINT Cream of the crop
}

William Tracy is one of only two sweetcorn breeders left in the US public sector. He describes how he is helping to grow a new generation of seed specialists as endowed chair at the University of Wisconsin-Madison - the first such position in the United States to focus on organic seed breeding.

\section{What is your mission?}

Public plant breeders do things companies don't, such as incorporating a range of genetic diversity. I develop new crop lines that companies can use to make hybrid varieties, and I use exotic corn from the tropics to give traits such as flavour, tenderness and appearance. Companies tend to focus on production qualities such as yield and disease resistance.

\section{How do your cultivars get to farmers?}

I've released around ten inbred lines, which companies have used to make dozens of different hybrid seeds. My lines are cost-free for research, but the companies return a royalty if they use one in a commercial cultivar. All the big seed companies have used my material. I calculated once that my lines have generated hundreds of millions of dollars in products.

\section{How is public plant breeding today different} from when you started your career?

When I was a PhD student in plant breeding in the 1980s, there were around 30 publicsector sweetcorn breeders, maybe 10 of them developing cultivars. Ten years later, there were around six or seven producing cultivars. Now, I'm basically it. Fifteen years ago, budgets were being cut and I was bemoaning the future of the discipline. It's better now, but the land-grant universities, where most public plant breeding took place, are being severely downsized. People aren't being replaced as they retire.

\section{What are the knock-on impacts?}

There are fewer training opportunities. The big seed companies realized that their training pipeline was drying up, and that is one reason things have got a bit better recently. Monsanto, DuPont and others started donating money to land-grant universities to fund graduatestudent training. But that shouldn't be the sole reason to have public plant breeding. We need to encourage a food supply based on genetic diversity.

\section{Have your trainees got jobs at public} universities?

None has gone to a public institution; some 40 have been hired by private companies.

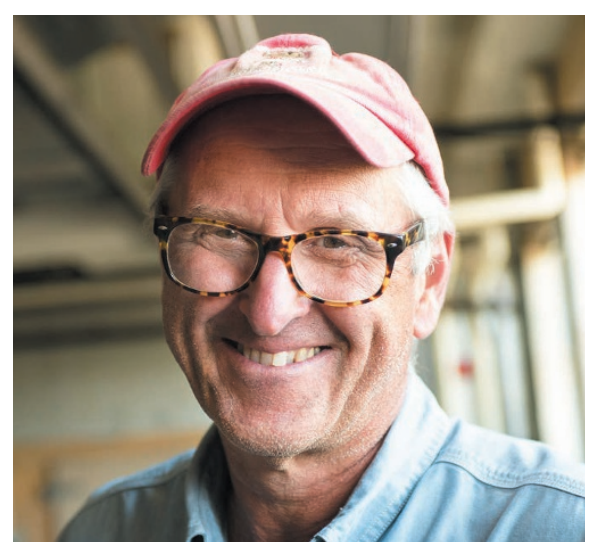

Is public crop breeding misunderstood?

The biggest misconception is that plant geneticists breed new cultivars. Molecular genetics and genomics produce a lot of papers but don't necessarily do anything to improve plant diversity on the farm - and that's where the crisis is.

Besides funding, what's your greatest problem? For those of us developing cultivars, it's increasingly difficult to get access to seed. Given the concerns about biopiracy - the use of seeds or knowledge for profit without a nation's consent - it can be almost impossible to collect seed in some countries. Despite international agreements meant to facilitate access to seeds and encourage equitable profit-sharing from their use, some countries still don't share, which can affect public- and private-sector breeding efforts.

\section{What is the significance of the new endowed} chair, funded by Clif Bar and Organic Valley? It shines a light on the need for organic plant breeding. Organic farms require crop varieties that are adapted to different soil environments, nutrient uptake strategies and microbial communities. But there hasn't been much breeding focused solely on organic crops. When these big companies fund not only the chair but also PhD-level fellowships, it generates interest from prospective students.

\section{What is your hope for the future?}

I'd really like to see the field move towards a greater understanding of the idea that classical plant breeding is a powerful means of developing new genetic diversity in crops. All of life's diversity is based on evolution, and plant breeding is really just human-directed evolution.

INTERVIEW BY VIRGINIA GEWIN

This interview has been edited for length and clarity. 